Vol. 4, $n^{\circ} 2 \mid 2000$

Varia

De la sûreté des campagnes. Police rurale et demandes d'ordre en France dans la première moitié du XIX siècle

\title{
Fabien Gaveau
}

\author{
(2) OpenEdition \\ Journals \\ Édition électronique \\ URL : https://journals.openedition.org/chs/824 \\ DOI : $10.4000 /$ chs.824 \\ ISSN : 1663-4837 \\ Éditeur \\ Librairie Droz \\ Édition imprimée \\ Date de publication : 1 juin 2000 \\ Pagination : 53-76 \\ ISBN : 2-600-00477-7 \\ ISSN : 1422-0857
}

Référence électronique

Fabien Gaveau, «De la sûreté des campagnes. Police rurale et demandes d'ordre en France dans la première moitié du XIX siècle », Crime, Histoire \& Sociétés / Crime, History \& Societies [En ligne], Vol. 4, $n^{\circ} 2$ | 2000, mis en ligne le 02 avril 2009, consulté le 22 mars 2022. URL : http:// journals.openedition.org/chs/824; DOI : https://doi.org/10.4000/chs.824 


\title{
De la sûreté des campagnes. Police rurale et demandes d'ordre en France dans la première moitié $d u X I X^{e}$ siècle
}

\author{
Fabien Gaveau'
}

Dans la première moitié du XIX siècle, la police rurale, dont les agents sont divers, est vivement critiquée par les notables. Ils dénoncent surtout l'attitude des gardes champêtres, théoriquement présents dans chaque commune. L'exagération rhétorique cache de rêelles défaillances. Certains suggèrent de réorganiser cette police. Cependant, l'embrigadement des gardes champêtres est toujours rejeté. Par delà les motifs financiers, le refus du projet repose sur des raisons essentiellement politiques, l'organisation de la police impliquant un débat sur l'État et la société.

In the first half of the XIXth century, the rural police, whose agents are varied, is strongly criticized by notables. They particularly denounce the attitude of the rural policemen, theoretically present in each commune. The rhetorical exaggeration hides real weaknesses. Some notables suggest reorganizing this police. However, rural policemen recruitment has always been rejected. Beyond financial motives, the refusal of this project is based on reasons that are essentially political, because the police organization implicates a debate about State and society.

ous la monarchie de Juillet, les modes de vie liés aux usages communautaires $D$ sont battus en brèche. La revendication du droit absolu d'user et d'abuser de son bien, associée parfois à un nouvel esprit agronomique, conduit des propriétaires à dénoncer la contrainte de sole, la vaine pâture et les droits d'usage. La montée de l'individualisme agraire s'accompagne d'une demande d'ordre pour faire respecter la propriété, fondement de la société au $\mathrm{XIX}^{\mathrm{e}}$ siècle. La police locale est ainsi placée au cour de débats qui s'amplifient dans les années 1840. Cette police se divise en une police municipale, qui s'exerce à l'intérieur des espaces bâtis, et une police rurale qui concerne les finages. Dans la pratique, les autorités différencient mal les attributions propres à l'une et à l'autre. Parmi les agents de l'ordre rural se trouvent les gardes champêtres dont l'emploi est rendu obligatoire dans chaque commune depuis la loi du 20 messidor an $\mathrm{IH}^{2}$. Or, ces derniers apparaissent comme le maillon faible d'une chaîne dont l'État souhaite qu'elle constitue une entrave à tous les

1 Fabien Gaveau, agrégé d'histoire, prépare une thèse à l'Université de Bourgogne sur le maintien de l'ordre dans le monde rural en France au cours du $\mathrm{XXX}^{\mathrm{e}}$ siècle (L'Ordre aux champs. Histoire des gardes champêtres (1791-1914), sous la direction de Jean-Marc Berlière. Il a publiê: Délinquance et pâturage dans le nord de la Côte-d'Or: l'accident, l'usage et le délit (1830-1850) in Garnot, B. (dir.), La petite délinquance du Moyen Âge à l'époque contemporaine, Dijon, Éditions universitaire de Dijon, 1998, pp. 361-371.

2 Loi du 8 juillet 1795, votée à la suite du rapport du Comité d'Agriculture présenté par Joseph Eschassériaux l'aîné, ancien conventionnel, député de Charente-Inférieure. 
fauteurs de trouble. Au cours des années 1840, des propositions de loi sont présentées au Palais Bourbon pour améliorer le maintien de l'ordre. À cette fin, l'embrigadement des gardes champêtres est suggéré en même temps que les conseils généraux exigent un maillage plus serré du territoire par la gendarmerie. Ces débats font écho aux plaintes formulées dans le pays. Cependant, malgré les vœux insistants en faveur d'une réforme, les députés, qui en reconnaissent le bien-fondé, ont repoussé l'adoption d'une loi pour y répondre. Comment comprendre ce rejet qui va à l'encontre d'un désir largement exprimé ? Après avoir décrit les moyens assurant la protection des biens et des personnes dans les campagnes sous la monarchie censitaire, je me pencherai sur la nature et l'étendue des plaintes qui en dénoncent les défaillances. J'étudierai enfin les solutions avancées pour y remédier et les raisons de leur rejet en 'm'intéressant en particulier à l'action d'un député du Lot, Félix de Saint-Priest.

\section{LES FORCES DE L'ORDRE EN MILIEU RURAL}

Dans la première moitié du siècle, la sûreté des campagnes relève d'un personnel divers soumis aux autorités administratives et militaires.

\section{Les pouvoirs de police des maires}

Dans chaque commune, le maire est le garant de l'ordre. Des pouvoirs de police administrative sont associés à ses fonctions. Il les exerce en prenant des arrêtés contrôlés par l'administration supérieure. L'éventail des situations concernées s'étend à tous les domaines du quotidien. Ainsi les maires doivent prévenir les incendies en faisant entretenir les fours et les cheminées et appliquer les lois limitant l'emploi du chaume dans les toitures. Ils assurent l'ordre public en réglementant l'activité des cabarets et des auberges. Ils encadrent les festivités et les rassemblements sur la voie publique. Ils président à ce titre les mises en adjudication de la garde des troupeaux ou de l'entretien des reproducteurs pour le cheptel du village. Ils prennent encore toutes les mesures pour assurer la libre circulation. Dans les faits, nombre de tas de fumier, de piles de bois et de gravats s'entassent le long des murs, devant les maisons, au bord des cours. La police du roulage leur incombe en partie, comme celle des marchés. Le finage fait l'objet d'une gestion attentive. Assisté des conseillers, le maire définit les espaces réservés au pâturage et élabore le règlement du parcours. Il organise en outre l'exercice des pratiques communautaires tel le glanage. Malgré l'abolition des bans de fauchaison et de moisson sous la Révolution, nombre d'entre eux prennent des arrêtés qui déterminent l'ordre dans lequel les contrées doivent être récoltées. Ils justifient ces mesures par la défense des propriétés. Enfin, les maires exercent des pouvoirs de police sanitaire pour le bien des personnes et des animaux. Ils doivent éviter le développement ou l'extension des épidémies et des épizooties. La peur de la rage les amène à surveiller de très près la divagation des chiens, nombreux dans les villages où les troupeaux sont fréquemment conduits au pâturage. La morve du cheval est tout aussi redoutée car elle entraîne la mort d'un animal de valeur. Là où le chanvre est cultivé et travaillé, les maires s'assurent que le rouissage n'entraîne pas la putréfaction des eaux courantes qui alimentent les bassins où les fibres se décomposent.

Outre cette police de prévention, le code d'instruction criminelle, adopté en 1808 et peu modifié sous la monarchie censitaire, fait des maires des officiers de 
police judiciaire ${ }^{3}$. Ils doivent rechercher les contraventions de police et recevoir les plaintes, les dénonciations et les rapports. Le décret du 12 février 1810, promulgué le 24 du même mois, définit la contravention comme «l'infraction que les lois punissent des peines de police ${ }^{4}$. Ces peines sont précisées par l'article 464 du code pénal: il s'agit de l'emprisonnement de un à cinq jours, de l'amende de un à quinze francs et de la confiscation de certains objets saisis. L'État a ainsi confié au maire les moyens de sanctionner la délinquance quotidienne. Il peut dresser procès-verbal contre ceux qui anticipent sur un espace public ou qui ne respectent pas les arrêtés de police. Les responsables de déprédations dans les récoltes, par destruction, vol ou pâturage illicite, risquent des poursuites judiciaires. Les maires sont d'ailleurs juges de police pour les contraventions donnant lieu à des dommages-intérêts inférieurs à quinze francs. Ils partagent là une compétence des juges de paix afin de régler promptement les délits courants et d'alléger la charge du tribunal de simple police. Cependant, si la partie qui réclame ne parvient pas à estimer le montant des dommages, seul le juge de paix est habilité à trancher l'affaire. Les maires ne semblent pas avoir jugé beaucoup. En revanche, leur action en matière d'arrangement et de conciliation était développée.

En somme, ils exercent dans les communes un pouvoir exécutif, réglementaire et judiciaire, incarnant les divers aspects de l'État. Pour éviter qu'ils se transforment en tyranneaux, leur action s'exerce sous la surveillance des autorités préfectorales. En 1812, le ministre de l'Intérieur Montalivet adresse aux préfets une circulaire destinée aux maires. Il y souligne qu'en vertu de la loi municipale de décembre 1789 et du décret sur les biens et usages ruraux de 1791, les maires servent l'État dans l'intérêt de la commune ${ }^{5}$. Suite à ce courrier, certains préfets ont rédigé des livrets rassemblant les obligations des maires en matière de police et destinés à chacun d'entre eux. Le préfet de la Creuse, Emmanuel Camus du Martroy, présente un exemplaire au ministre pour approbation dès le 24 décembre $1812^{6}$. Ces mesures sont répétées sous la monarchie censitaire. Toutefois, l'information des maires se heurte à leur incompétence ou à l'inertie de certains préfets. Pour corriger ces faiblesses, l'État choisit autant que possible des hommes de confiance pour le servir et le représenter. Là où les intérêts politiques sont réduits, les préfets se contentent de désigner comme maire la personne la plus capable et dont chacun sait qu'elle n'est pas ouvertement hostile au gouvernement. La révocation donne d'ailleurs les moyens de corriger une nomination malheureuse. En outre, le maire n'est pas seul en charge du maintien de l'ordre. Il exerce ses pouvoirs de police et de justice concurremment avec d'autres responsables comme les gendarmes.

\section{La place de la gendarmerie}

Les tâches de la gendarmerie ont été précisées au début de la Restauration par l'ordonnance royale du 29 octobre 1820 . L'article 1 stipule qu' «une surveillance continue et répressive constitue l'essence de son service». Elle est en charge de la

3. Code d'instruction criminelle, Livre I, chapitre II, articles 11 à 15.

4 Code pénal, dispositions préliminaires, article $1^{\mathrm{er}}$.

5 Archives nationales [A.N.], $F / 2(I) / 129 / 2$, police municipale et rurale 1812-1813, circulaire $\mathrm{n}^{\circ} 126$, du 22 octobre 1812 envoyée aux préfets le 10 novembre 1812 .

6 Ibidem, Instructions aux maires et adjoints du département de la Creuse sur la police municipale et rurale, $12 \mathrm{p}$. 
police judiciaire sur l'ensemble du territoire et intervient plus particulièrement dans les campagnes. Il existe des brigades à pied et des brigades montées, moins nombreuses car d'entretien plus coûteux. Le nombre de gendarmes passe d'environ 14000 en 1842 à 15200 en 1847 puis connaît une brusque hausse jusqu'à 18000 en 1852. Dans le même temps, le nombre de brigades passe de 2564 à $3290^{7}$. Cependant, dans la première moitié du XIX $\mathrm{XI}^{c}$ siècle, elles quadrillent très inégalement le territoire. En 1845 , plus de trois cents cantons en sont dépourvus ${ }^{8}$. En Saône-et-Loire, vingt et un n'en ont pas. Les conseils généraux émettent de nombreux vœux pour compléter une couverture cantonale bien mitée. Ils ne tiennent que partiellement compte des demandes émises à ce sujet par les conseils d'arrondissement. Dans les années 1820, le conseil général de Saône-et-Loire porte ses efforts sur l'obtention d'une brigade à Lucenay-l'Évêque, sur une route royale, entre Saulieu et Autun, mais refuse d'appuyer les vœux de Paray et Chauffailles'. Celui de Côte-d'Or obtient à la même époque une brigade à Montigny-sur-Aube et en réclame une autre à Flavigny-sur-Ozerain puis à Châtillon-sur-Seine où le développement de la sidérurgie fait gonfler la population ouvrière ${ }^{10}$. La Creuse ne compte que quinze brigades en 1833, dix-sept en 1836. Cependant, les petits notables peinent à en obtenir de nouvelles. Dans le canton de Châtelus-Malvaleix, ils réitèrent en vain pendant plus de trente ans le même souhait ${ }^{11}$. Dans l'Hérault, il n'y a que vingt-trois brigades en 1825 dont quatre à Montpellier et Béziers. En 1845, leur nombre reste inférieur à trente ${ }^{12}$. De 1844 à 1851, le conseil général du Lot suggère l'installation d'une gendarmerie «dans chaque chef-lieu de canton du département» "3. Toutefois, les notables ont conscience de l'effort financier qu'exige un tel ajustement. Les autorités militaires n'hésitent d'ailleurs pas à souligner la responsabilité de la Chambre dans le difficile déploiement de la gendarmerie. En 1841, le préfet de la Creuse rapporte au conseil général qu'une discussion «avec $\mathrm{M}^{\mathrm{r}}$ l'Inspecteur général de l'arme (lui) donne à penser que l'institution de nouvelles brigades sera chose difficile tant que les crédits législatifs pour la gendarmerie ne seront pas augmentés $»^{14}$. Les notables formulent alors des priorités, à l'instar du conseil général du Lot qui avance l'urgence à installer des brigades à Livernon, Catus et Bretenoux.

Les gendarmes incarnent véritablement l'ordre. Leur présence et les pouvoirs de répression dont ils sont dotés rassurent les notables. Ils appartiennent à un corps clairement structuré et hiérarchisé qui relève de l'autorité militaire mais ne dépend pas de multiples chefs. Il en découle une efficacité d'action car la gendarmerie est indépendante des pouvoirs locaux qu'elle contribue à surveiller. D'ailleurs, les procureurs louent l'efficacité et le zèle de ces hommes dont la seule faiblesse tient au faible nombre. Dans l'absolu cependant, d'autres forces participent au maintien de l'ordre dans les campagnes.

7 D'après Aubusson de Cavarlay, Huré et Pottier (1989, p. 159).

8 Le Moniteur Universel (1845, p. 1452).

9 Archives départementales de Saône-et-Loire [A.D.S.L.], N/5 et N/6, sessions de 1823 à 1829.

10 Archives départementales de la Côte-d'Or [A.D.C.O.], $1 / \mathrm{N} / \mathrm{c} / 2$ et $1 / \mathrm{N} / \mathrm{c} / 3$, sessions des années 1820 1830.

11 Archives départementales de la Creuse [A.D.C.], 1/N/3 et $1 / N / 4$, rapports du préfet au conseil général, 1825-1841.

12 Annuaire statistique de l'Hérault, années 1825 et 1845.

13 Archives départementales du Lot [A.D.L.], 1/N/28, session de 1844.

14 A.D.C., 1/N/4, rapport du préfet en 1841. 


\section{Les gardes ruraux}

Le code forestier, entré en vigueur au $1^{\mathrm{er}}$ janvier 1829 , organise un corps de gardes chargés de la protection des bois domaniaux et communaux soumis au nouveau régime. Certains exercent à cheval, d'autres à pied. Tous appartiennent à une hiérarchie soumise aux conservateurs et aux inspecteurs des Forêts. Néanmoins les préfets et les communes ont la charge exclusive de leur nomination. En outre, la loi du 15 avril 1829 relative à la pêche fluviale définit le service des gardes-pêche. L'article 37 stipule que, nommés par l'administration, ils sont assimilés aux gardes forestiers royaux. Tous sont officiers de police judiciaire et à ce titre soumis à la surveillance des procureurs. Leur nombre total atteint de 1847 à 1852 un record au XIX $^{\mathrm{e}}$ siècle avec environ 10000 hommes, d'après les rapports des procureurs ${ }^{15}$. La gestion de ce corps implique des échanges réguliers entre l'administration préfectorale et celle des Domaines, dépendant du ministère des Finances. À la différence des gendarmes, ces agents sont soumis à plusieurs autorités. Les gardes forestiers doivent ménager les maires qui les emploient et qui fixent, en accord avec le conseil municipal, leur salaire au moyen d'un rôle portant sur chaque foyer et établi au moment de distribuer les affouages.

Ils voisinent avec les gardes champêtres communaux, dont l'effectif officiel varie de 33500 à 35000 dans les années $1840^{16}$. Leurs compétences et leur cadre d'action recoupent ceux des forestiers. L'article 16 du code d'instruction criminelle stipule que tous ces employés «sont chargés de rechercher, chacun dans le territoire pour lequel ils auront été assermentés, les délits et les contraventions de police qui auront porté atteinte aux propriétés rurales et forestières ». Depuis messidor an III, de nombreuses mesures sont venues définir plus particulièrement l'organisation et les compétences des gardes champêtres. Ils doivent prêter le serment politique et professionnel pour être installés. Conformément à l'article 13 de la loi municipale du 18 juillet 1837, ils sont choisis et nommés par les maires. Dès lors, le choix n'a plus à être soumis à l'approbation des conseillers municipaux, comme cela était le cas depuis 1820. Les sous-préfets contrôlent les nominations puisqu'ils agréent ou refusent les recrues. Les préfets sont seuls habilités à prononcer une révocation. Certains sont heurtés par ce principe jugé contraire à l'usage selon lequel les pouvoirs de nomination et de révocation sont habituellement entre les mêmes mains. Le premier président de la Cour de cassation, le baron Henrion de Pansey, s'insurgeait déjà de cet état à propos de l'ordonnance du 29 novembre 1820 sur les gardes champêtres. Son article 2 consacré aux modalités de destitution lui semblait contraire à la règle ejus est destituere cujus est instituere ${ }^{17}$. Enfin, outre la surveillance des procureurs, tous les gardes doivent se présenter au brigadier de gendarmerie, qui, en application de l'article 310 de l'ordonnance royale du 29 octobre 1820, est tenu d'en consigner les noms, âges et domiciles sur un registre. Les gendarmes peuvent les réquisitionner «dans des cas urgens, ou pour des objets importants ${ }^{18}$ après avoir averti les autorités civiles. Par cette disposition, le second ministère Richelieu estime pallier le médiocre encadrement policier des campagnes.

15 D'après Aubusson de Cavarlay, Huré et Pottier (1989, p. 159).

16 Ibidem.

17 CEuvres judiciaires du président Henrion de Pansey (1844, p. 407).

1s Article 312 de la loi du 29 actobre 1820. 
Au début du Second Empire, la loi maintient la distinction entre un garde champêtre, au service des propriétés rurales, et un agent de police, établi pour les localités. Pourtant, le dernier article des arrêtés de police municipale confie couramment l'exécution des mesures au garde champêtre. En 1816, le préfet de Côte-d'Or, Hervé de Tocqueville, rédige un manuel à leur intention. Il précise qu' «ils peuvent être et sont ordinairement commissionnés en qualité d'agent de police» ${ }^{19}$. L'étude des registres des justices de paix confirme que peu d'entre eux ont prêté serment à ce double titre. La plupart n' ont pas, si l'on interprète strictement le droit, le pouvoir de verbaliser dans les villages pour des délits autres que ruraux. Enfin, ils côtoient des gardes particuliers, employés pour surveiller un domaine privé. Il arrive que le garde champêtre communal soit en même temps garde particulier. Ces cas suscitent un doute quant au zèle mis à protéger les biens de tous les villageois.

En définitive, maires et adjoints exclus, le nombre total d'agents enregistrés par les statistiques ministérielles et servant l'ordre dans les campagnes - ce qui met de côté les gardes nationales et l'armée - s'élève à environ 87420 en 1845 et 91200 en 1851. Le rapport à la population considérée comme rurale dans les limites de la France de l'époque ${ }^{20} s^{\prime}$ 'établit à un agent pour trois cent six ruraux en 1845 et à un pour deux cent quatre-vingt-treize en 1851 . Le tableau suivant permet de cerner les grands traits de l'évolution des effectifs sur cette période ${ }^{21}$.

\section{Tableau 1:Évolution des effectifs et de la composition des forces de l'ordre à la campagne de 1845 à 1851 .}

\begin{tabular}{|c|c|c|c|c|}
\hline Nombre & $\begin{array}{c}1845 \\
\%\end{array}$ & 1851 & $\begin{array}{c}\text { Variation } \\
1845-1851 \\
\%\end{array}$ & $\begin{array}{c}\text { Contribution } \\
\text { à la variation totale } \\
\text { des effectifs } \\
1845-1851 \\
\%\end{array}$ \\
\hline Gendarmes & $14.685 \quad 16,8$ & $17.041 \quad 18,7$ & $+2.356+16$ & 62,2 \\
\hline Gardes champêtres & $34.431 \quad 39,4$ & $35.025 \quad 38,4$ & $+594+1,7$ & 15,7 \\
\hline Gardes pêche et forestiers & $9.832 \quad 11,2$ & $9.865 \quad 10,8$ & $+33+0,3$ & 0,9 \\
\hline Gardes particuliers & $28.472 \quad 32,6$ & $29.276 \quad 32,1$ & $+804+2,8$ & 21,2 \\
\hline Total & $87.420 \quad 100$ & $91.207 \quad 100$ & $+3.787+4,3$ & 100 \\
\hline
\end{tabular}

19 Tocqueville (1816, p. 4). L'exemplaire consulté est conservé aux A.D.C.O., E-dep $/ 316 / 46$, chemise $\mathrm{K} / 4 / 1-17$. Versement de la commune de Grignon (canton de Montbard), ce qui montre que la brochure a été diffusée.

20 D'après Dupâquier (1995, pp. 129-136). La population rurale de la France, sans le comté de Nice, la Savoie et la Haute-Savoie, est d'environ 26,80 millions en 1845 et de 26,70 millions en 1851 .

21 Effectifs d'après Aubusson de Cavarlay, Huré et Pottier (1989, p. 159). En gras, les données les plus élevées (hors total). 
De 1845 à 1851, deux catégories d'agents ont particulièrement été développées: les gendarmes et les gardes particuliers. Si les gardes champêtres continuent à former le gros des troupes, leur part relative diminue dans le total des forces de l'ordre. Certes, la croissance de leur nombre réel contribue pour près de $16 \%$ au renforcement de l'encadrement policier des campagnes mais, à l'instar des gardes relevant des Eaux et Forêts, il n'est guère possible de créer ni de supprimer beaucoup de postes. En effet, la loi impose au minimum un garde par commune ou cantonnement. Le plus souvent des emplois ont été ouverts là où les municipalités n'avaient pas encore de garde. En revanche le nombre de gendarmes, rétribués par l'État et logés grâce aux conseils généraux, augmente fortement, signe de l'effort des gouvernements et des départements. Enfin l'accroissement du nombre des gardes particuliers ne s'explique pas seulement par leur meilleur comptage mais aussi par une exigence de sécurité forte qui reflète des insatisfactions grandissantes à l'égard des institutions publiques de maintien de l'ordre.

\section{LES INSATISFACTIONS EN MATIÈRE DE POLICE RURALE}

Des plaintes et des rapports s'accumulent sur les bureaux des administrateurs depuis le Directoire pour dénoncer les lacunes de la police rurale et les défaillances des gardes champêtres.

\section{Des gardes champêtres incompétents et délinquants?}

Balzac utilise la figure du garde délinquant dans son roman Les Paysans, écrit à partir de 1834. Il en fait un instrument de la communauté villageoise attaquée par des propriétaires hostiles aux droits d'usage. Sous sa plume, le garde, qui doit servir l'État, devient l'auxiliaire de délinquants et de petits notables ruraux attachés au pouvoir municipal. En outre, sa moralité paraît douteuse. «Vaudoyer, le gardechampêtre destitué, p̃aysan de Ronquerolles, n'était, comme la plupart des gardeschampêtres, propre qu'à se promener, niaiser, se faire choyer par les pauvres qui ne demandent pas mieux que de corrompre cette autorité subalterne, la sentinelle avancée de la Propriété $»^{22}$. À la fin du siècle, Zola emploie à nouveau ce type d'image dans La Terre. De telles accusations ne sont pas le seul fruit d'une recherche littéraire. Les procureurs et les prefets insistent dans leurs relations avec les ministères de la Justice et de l'Intérieur sur les dysfonctionnements relatifs à la police rurale. Quelques exemples permettent de connaître les critiques les plus fréquentes.

En l'an X, le préfet de Côte-d'Or stigmatise les gardes «qui ont plutôt besoin d'être surveillés que de surveiller les autres ${ }^{23}$. La même année, celui de Charente $s$ 'inquiète de la multiplication des délits dans son département, comme dans celui des Hautes-Alpes, où il était en poste. Il estime «que les moyens de répression sont à peu près nuls $»^{24}$. En 1814, un successeur soupçonne les gardes «d'abus répréhensibles » dans leur service. Ce soupçon est une certitude pour son collègue d'Indre-et-

22 Balzac (1993, p. 185).

23 A.N., F/2(I)/1206, Côte-d' Or, rapport au ministre de l'Intérieur du 14 floréal an X.

24 A.N., F/2(I)/1206, Charente, rapport au ministre de l'Intérieur du 11 thermidor an X. 
Loire en $1816^{25}$. Le préfet de la Meurthe regrette en 1826 l'incompétence de gardes qui ignorent le français ou qui sont malhonnêtes ${ }^{26}$. Des plaintes similaires s'élèvent de toute part pendant plus de cinquante ans. Or, les gardes champêtres n'ont pas toujours le sentiment de mal agir tel celui de cette commune de Côte-d'Or, révoqué en janvier 1850 parce qu'il a plusieurs fois manqué à ses devoirs. La gendarmerie rapporte qu'il a laissé des jeunes chasser les 4 et 5 décembre 1849 , promettant l'impunité s'ils acceptaient de partager avec lui le repas de Saint Nicolas ${ }^{27}$. Pour le garde, ce n'est pas un acte de braconnage que de se procurer du gibier pour fêter les trente ans d'hommes célibataires. Il n'a pas voulu entraver la préparation d'une réjouissance habituelle à laquelle les autorités locales s'associent généralement. L'idée de corruption semble étrangère à un geste que justifie une tradition. Pourtant la Cour de cassation rappelait en 1837 que «le crime de concussion, de la part des fonctionnaires ou officiers publics, ne consiste pas seulement à exiger, mais aussi à recevoir, à l'occasion d'un acte de leurs fonctions, ce qu'ils savent ne pas leur être dû pour salaire ou traitements». Il s'agit alors de casser un arrêt de la cour de Poitiers qui relaxe un garde champêtre ayant reçu «diverses sommes d'argent et une bouteille de vin» de femmes qu'il a trouvées en délit et contre lesquelles il n'a pas dressé procèsverbal $^{28}$. Il a favorisé un arrangement entre le propriétaire lésé et les délinquantes et a été dédommagé pour sa médiation infrajudiciaire. Pour un cas jugé, beaucoup d'autres échappent à une queiconque sanction. Enfin, les préfets dénoncent l'emploi d'individus trop assidus des cabarets, ce qui corrompt à la fois leur vigilance et leur opinion. Ils notent également la persistance de communes dépourvues d'un garde car elles n'en éprouvent pas le besoin, n'en ont pas les moyens ou refusent cette charge, situation courante dans les départements du Massif central, de l'Ouest et du Sud-Ouest.

En somme, un premier type de plaintes porte sur l'incompétence des gardes champêtres. L'emploi d'invalides et de vieillards est vivement critiqué. Or, la loi fixe seulement un âge minimum - 25 ans - pour accéder au poste. Elle s'en remet implicitement à la sagesse des maires et des conseils pour écarter les personnes inaptes. Pourtant, le décret impérial du 8 mars 1811 arrête qu'un ancien soldat dont les infirmités proviennent de blessures de guerre peut devenir garde. La mesure vise à faciliter le retour d'une partie des militaires de la Grande Armée à la vie civile. Dans les faits, les gardes touchés par une incapacité physique sont moins nombreux que les discours ne le laissent croire. En 1812, ils ne sont que quatorze sur les trois cent quinze recensés dans les Hautes-Pyrénées, soit $4,5 \%$ de l'effectif ${ }^{29}$. Dans les Hautes-Alpes, deux des cent soixante-quatre gardes installés en 1821 sont infirmes, soit $1,2 \%$. Ils seront d'ailleurs révoqués ${ }^{30}$. De plus, l'institution judiciaire fait souvent observer qu'ils ne savent ni lire ni écrire, ce qui entrave le constat des délits.

25 A.N., F/2(I)/1206, Charente, arrêté du 30 juillet 1814 sur la police rurale et F/2(I)/1208, Indre-etLoire, lettre du 16 juillet 1816 au ministre de l'Intérieur.

26 A.N., F/2(I)/1208, Meurthe, rapport au ministre de l'Intérieur du 10 août 1826.

27 A.D.C.O, 2/O/149/1, rapport de décembre 1849 concernant le garde de Channay (canton de Laignes).

28 Arrêt de la Chambre Criminelle de la Cour de cassation du 5 mai 1837.

29 Archives départementales des Hautes-Pyrénées [A.D.H.P.], 4/M/19, recensement des gardes champêtres et forestiers du département par la gendarmerie, 1812 .

30 Archives départementales des Hautes-Alpes [A.D.H.A.], 1/O/14021, cahiers de suivi des gardes en exercice, 1821 et 1827. 
Cependant, l'attribution de la place à des personnes instruites est recommandée par l'État et non imposée. En effet, un autre officier de police judiciaire peut rédiger le rapport que le garde affirme devant lui. Enfin, la méconnaissance du droit est constamment soulignée, bien que les préfets s'évertuent à répandre des livrets qui synthétisent les obligations du service.

Un deuxième type de plaintes concerne l'inconduite des gardes champêtres. L'administration interprète le faible nombre de procès-verbaux qu'ils dressent comme un signe de négligence voire de complaisance à l'égard des délinquants. En fait, ils facilitent le règlement des querelles et des délits entre les personnes concernées en leur évitant une action en justice. En outre, leur délinquance n'est pas générale. Le préfet Tocqueville note à l'occasion de son inspection des communes de Côte-d'Or en 1816 que la plupart essaient de remplir convenablement leurs fonctions ${ }^{31}$. Dans les Hautes-Alpes, sur cent soixante-quatre gardes champêtres installés en 1821 , quatre-vingt-neuf sont encore en activité dix ans après soit $54,3 \%$. Trentesept, soit $22,5 \%$, ont démissionné de leur plein gré sans que leur service ne soit en cause. Une poignée, sept, soit $4,3 \%$, ont bénéficié d'une promotion dans le corps des gardes forestiers voire dans la gendarmerie. Ainsi, $81,1 \%$ des gardes ont rempli leur tâche convenablement. Toutefois, trente et un, soit $18,8 \%$ ont été révoqués, dont dixhuit pour inconduite, soit environ $10 \%$ des effectifs de 1821. Enfin, les ivrognes notoires ne sont que trois dans les Hautes-Alpes en $1827^{32}$. Ces données permettent de nuancer l'image de gardes majoritairement malhonnêtes, alcooliques et incompétents. Certes, dans les départements, ceux qui donnent pleine satisfaction sont souvent peu nombreux. Ils ne représentent que $16 \%$ de l'effectif dans les HautesPyrénées en 1812. Toutefois, pour l'immense majorité des gardes, l'administration ne se prononce pas. Elle s'en remet aux communes pour écarter les incompétents et n'intervient directement que lorsque les mécontentements sont trop prononcés.

La question de l'incompétence repose en partie sur une perception différente de l'ordre entre les villages et l'administration. Ainsi, vers 1840 , des conflits surgissent dans de nombreuses communes autour des pratiques communautaires et de l'utilisation des biens communaux. Les affaires se renouvellent selon une trame assez proche d'un lieu à l'autre. Des villageois dénoncent à l'administration un garde champêtre accusé de complaisance à l'égard de ceux qui profitent des droits d'usage. Les crises qui apparaissent alors traduisent le heurt entre des normes héritées de 1'Ancien Régime et une conception individualiste de la propriété, liée au sens du profit, à l'intérieur des communes. Deux familles de références s'affrontent, la coutume et la loi. L'une est défendue comme immémoriale et inhérente à l'organisation de la communauté, et l'autre est reconnue comme seule valable par les représentants de l'État et les exploitants qui s'engagent dans une agriculture nouvelle. Situés à la jonction de ces normes, les gardes concentrent les attaques de réseaux qui s'opposent pour la gestion des terres, tout en étant bien souvent euxmêmes impliqués dans ces luttes.

31 A.D.C.O., 1/M/223, Journal de tournée du 24 avril au 31 octobre 1816.

32 A.D.H.A., 1/O/14021, la statistique repose sur le suivi jusqu'en 1831 des gardes nommés en 1821 dans les trois arrondissements du département. En 1827, 201 gardes sont répertoriés. 


\section{La question du traitement des gardes}

Quelques arguments sont systématiquement repris pour expliquer les défaillances observées. La question du traitement des gardes champêtres est posée depuis la Révolution. En effet, dès l'an V, nombre d'administrations départementales font de sa résolution la condition essentielle à l'établissement et à la qualité d'une police rurale.

Le directoire exécutif de l'arrondissement de Soissons informe en messidor an V le ministère de la Justice qu'il ne faut pas imaginer «que des hommes, qui ne retirent de l'exercice des fonctions qui demandent une vigilance toujours active, qu'un salaire trop modique pour pouvoir subsister sans autre ressource, donneront tout leur temps à ces mêmes fonctions ${ }^{33}$. De tous les départements, des plaintes font savoir dès cette époque que les communes sont dans l'incapacité à assurer un traitement convenable aux gardes champêtres. Les dépenses qu'elles supportent s'accroissent: chemins, bâtiments, écoles, secrétariat... S'y ajoutent les prélèvements au service de l'Empire jusqu'en 1814. La fiscalité locale s'organise lentement et difficilement. La loi du 15 frimaire an VI fait du salaire des gardes une dépense communale obligatoire. L'année suivante, les municipalités de canton en sont chargées. La façon de lever le salaire reste imprécise pour les administrateurs locaux bien que le ministère de l'Intérieur les inondent de rappels. Jusqu'en l'an VI, le produit des amendes attribuées aux communes est censé le former. En cas d'insuffisance, il est théoriquement complété par une contribution au marc la livre de l'imposition foncière. Ce système fonctionne très mal et la plupart des communes ne parviennent pas à payer leur garde, entraînant leur négligence ou leur démission et un improbable remplacement.

Une note de l'administration départementale du Lot-et-Garonne permet d'en deviner les motifs. Elle se plaint en l'an VII de ce que les receveurs refusent de mettre à disposition des communes le produit des amendes. Saisi, le ministre de l'Intérieur tente d'infléchir son collègue des Finances afin qu'il revienne sur une mesure préjudiciable à la protection des récoltes. Soutenu par le ministre de la Justice, qui fait valoir que la loi du 20 messidor an III ne prévoit pas le paiement des gardes au moyen des amendes, celui des Finances refuse de se plier aux exigences de l'Intérieur ${ }^{34}$. Ainsi, une mauvaise coordination des trois ministères, envoyant à leurs subordonnés des circulaires divergentes, a paralysé la gestion de la police rurale. Quelques années plus tard le problème se renouvelle. En 1802, le préfet de l'Aisne observe que dans les communes « où les revenus sont nuls, ce qui fait le plus grand nombre depuis la loi du 10 juin 1793, les centimes additionnels, quoiqu'imposés généralement au maximum de cinq, sont à peine suffisants pour subvenir aux autres charges annuelles ${ }^{35}$. Les partages et les ventes des biens communaux ont amputé les recettes communales dont le produit n'est pas affecté en priorité à la rétribution d'un garde champêtre. Le ministre rétorque que les municipalités ont été rétablies depuis 1800 dans la jouissance du produit des amendes pour les utiliser à cette fin. Or, en l'an XIII, une vaste enquête révèle que l'institution judiciaire ne donne guère de bilan des amendes prononcées au profit des communes. Cette lacune se double des défaillances de l'administration des Finances qui communique très

33 A.N., F/2(I)/1205, Aisne, lettre du 3 messidor an V.

34 A.N., F/2(I)/1209, Lot-et-Garonne, pièces du 26 brumaire an VII, $\mathrm{n}^{\circ} 1434$, émises par le Bureau d'Agriculture.

35 A.N., F/2(I)/1205, rapport au ministre de l'Intérieur du 26 messidor an X. 
inégalement aux préfets l'état des recettes venant des condamnations. La régie du Domaine a par ailleurs tendance à ne pas attribuer aux municipalités les sommes qui leur reviennent. Les préfets du Bas-Rhin, du Doubs, de Côte-d'Or, du Var, du Loiret, d'Indre-et-Loire, de la Vienne et de Gironde se plaignent de cet état de fait ${ }^{36}$. L'absence de coordination entre les trois ministères demeure. Pour sortir de l'impasse, certains demandent à revenir à un mode ancestral de paiement. Il s'agirait de réunir le salaire des gardes au marc la livre d'une contribution foncière portant sur les biens réellement placés sous leur protection. Elle serait payée par les exploitants, non les propriétaires. Le ministère de l'Intérieur s'y oppose. Il faut attendre les années 1830 pour que se clarifie la rétribution des gardes champêtres. L'article 19 de la loi du 21 avril 1832 stipule ainsi qu'il ne sera plus fait de rôle pour le paiement de leur salaire. Il sera supporté par la contribution foncière portant sur tous les types de propriétés non bâties. La prise en compte ou non des propriétés closes soulève alors de nouvelles discussions visant à fixer ce que 1'on entend par clos.

De grandes disparités caractérisent les traitements des gardes champêtres. Dans les années 1830, ils reçoivent généralement entre cent et trois cents francs à l'année dans la France riche du Nord et de l'Est. En revanche, les salaires s'abaissent entre cinquante et cent francs dans les départements plus pauvres de l'Ouest et du Sud. Dans les Hautes-Alpes, certains exercent pour dix francs à l'année. Dans ces conditions, un garde doit compter sur d'autres revenus pour répondre à ses besoins et à ceux de sa famille. La comparaison avec les salaires d'autres employés municipaux n'est pas aisée car chaque commune fixe ce type de dépenses en proportion des revenus dont elle dispose. À la lumière des sources dépouillées, il apparaît que les gardes forestiers gagnent aux alentours de deux cents francs en Côte-d'Or dans les années 1830 , soit l'équivalent des gardes champêtres. Les autres employés sont bien moins payés à l'image des secrétaires de mairie. Quant aux instituteurs, la loi Guizot de 1833 oblige les communes à leur verser au moins deux cents francs, qu'une rétribution portant sur chaque élève vient augmenter. En outre, il est fréquent que le garde champêtre ajoute à son traitement une petite somme pour être appariteur ou cantonnier. Il peut en effet conjuguer ces activités qui l'amènent à parcourir le finage. En définitive, quand il reçoit trois cents francs, il gagne autant qu' un journalier agricole travaillant sur une exploitation vers 1840.

Les préfets regrettent que les gardes ne soient pas assez rétribués pour être à l'abri de la corruption et pour surveiller constamment les propriétés. Cependant, leur analyse est tronquée parce qu'ils font de cette fonction une profession à part entière, qui doit permettre à son titulaire de vivre de ce seul salaire. Or, les ruraux ne partagent pas une telle conception. La protection des terres est une charge lourde et délicate qui concerne tous les propriétaires et tous les exploitants. L'un d'eux accepte temporairement de rendre service à la collectivité en assumant cette responsabilité. La contrepartie du fardeau est souvent - mais pas toujours jusque sous la Restauration - une rétribution en argent. De plus, dans les villages, les volontaires ont des préoccupations diverses. Dans la première moitié du XIX ${ }^{e}$ siècle, la fonction reste largement occupée par des individus qui n'ont pas été militaires. La proportion d'anciens soldats parmi ces agents est particulièrement faible dans certaines régions de France, y compris après la dissolution de régiments sous la Restauration. En 1812, dans les Hautes-Pyrénées, seulement six des trois cent quinze recensés sont

36 A.N., F/2(I)/130/1, enquête de 1813 au sujet des amendes attribuées aux communes. 
d'anciens soldats, soit $2 \%$ du total. La proportion est à peine plus élevée en 1821 dans les Hautes-Alpes: sur les quatre-vingt-sept gardes nommés dans l'arrondissement de Gap seulement trois sont d'anciens militaires, soit 3,5\%. Dans le Nord et l'Est de la France, la proportion, plus élevée, ne permet pas de conclure que le poste était une issue pour les anciens militaires. Si les gardes sont jeunes, il est courant qu'ils attendent d'hériter d'une exploitation familiale sur laquelle ils continuent de travailler. Ceux qui sont aussi artisans équilibrent leurs revenus. En effet, ils peuvent grouper leur activité artisanale pendant les mois d'hiver et veiller sur le finage du printemps à l'automne, période de pleine activité agricole. Nombreux sont ceux qui disposent de quelques terres et en retirent des ressources. Parfois, la fonction est occupée par un individu âgé qui trouve à s'occuper et à compléter un fermage ou une pension versée par des enfants. Dans tous les cas, les revenus habituels sont rehaussés. Cependant, cette situation présente des inconvénients. La modeste extraction sociale des gardes les place, comme leurs proches, dans une dépendance prononcée à l'égard d'employeurs, qu'ils verbalisent difficilement. De plus, la fonction est souvent brièvement occupée. Il convient donc de ménager ceux qui pourraient éventuellement procurer un travail. Cette dépendance prend des formes diverses et constitue un autre motif de mécontentement des préfets et des notables.

\section{La dépendance des gardes à l'égard des maires}

Jusqu'en 1820, la nomination des gardes champêtres suit des modes variés comme en témoigne un rapport adressé au Comité de l'Intérieur et au roi le 30 août 1820. Ce sont tantôt les conseils municipaux, tantôt les maires qui les installent. Quand le salaire prévu atteint ou dépasse 180 francs, les sous-préfets les commissionnent. Il en suit des relations diverses entre les gardes et les autorités locales ${ }^{37}$. Le préfet des Hautes-Alpes se plaint le 7 août 1820 au directeur général de l'administration départementale et de la police de cette situation. D'après lui, «les gardes champêtres nommés par les communes sont souvent révoqués par le caprice ou sur le mécontentement de quelques conseillers municipaux influents [...], que par suite de cette dépendance ces agents, pour éviter leur renvoi, ou par crainte de se créer des ennemis, ne font point ou font mal leur service [...], négligence qui met encore les gardes dans le cas d'être révoqués justement par les conseils municipaux. Il en résulte une mobilité nuisible dans le personnel de ces agents ». Il termine en déclarant que «c'est précisément dans les communes les moins éclairées qu'ils sont le plus livrés à l'arbitraire des fonctionnaires locaux ${ }^{38}$. En revanche, il lui semble utile de généraliser la délivrance d'une commission par le sous-préfet et de donner le pouvoir de révocation au préfet. L'ordonnance du 29 novembre 1820 est le fruit de ces remarques. Le choix revient au maire, qui présente au conseil municipal le candidat au poste de garde. Le sous-préfet le commissionne et seul le préfet peut le destituer. Il s'agit de clarifier le mode de nomination et non d'envisager une réforme d'envergure qui nécessiterait un examen aux Chambres. Certes, le contexte politique momentanément favorable au ministère permet de renforcer le contrôle de l'administration centrale sur les communes tout en préservant le pouvoir des maires ${ }^{39}$.

\footnotetext{
37 A.N., F/2(I)/1210, Nord, rapport du 30 août 1820.

38 A.N., F/2(I)/1210, Nord, lettre du préfet des Hautes-Alpes reçue le 7 août 1820.

39 Les élections de novembre 1820 dégagent une majorité à droite avec le retour en force des ultras représentés dans le ministère par Villèle et Corbière.
} 
Toutefois, un projet de loi déposé le 22 février suivant afin d'accroître plus largement cette emprise révèle l'absence de docilité des parlementaires. L'opposition conjointe de la droite et de la gauche oblige le ministère Richelieu à retirer le projet dans l'été.

Très rapidement, des protestations s'élèvent contre l'ordonnance de novembre. En 1821, un notable du Tarn estime que c'est une grave erreur de confier aux municipalités le choix des gardes. Il en découle immanquablement des compromissions nuisibles à l'ordre. Son expérience lui sert d'argument: «J'ai pu me convaincre lorsque j'ai été maire que des traités ou accords ont été faits et exécutés entre plusieurs membres du conseil municipal et le garde champêtre pour que sa surveillance ne s'étendit pas dans leur canton $»^{40}$. Il préconise l'intervention des grands propriétaires dans les nominations. Le préfet du Nord donne un autre point de vue en demandant à ce que seuls les sous-préfets puissent choisir et nommer les gardes car les maires et les conseillers sont «bien assurés que ces agents fermeront les yeux sur les délits qu'ils commettent». Il souligne qu'avec des gardes étrangers au village, «les complaisances, les considérations de parenté et de convenance cesseraient». En l'état, «les maires confient ces emplois à leurs propres domestiques ou à leurs créatures $»^{41}$. Cette remarque traduit une réalité que l'administration a beaucoup de mal à corriger.

Les gardes champêtres sont communément originaires de la commune qu'ils servent ou y vivent depuis de longues années. Il convient en effet de connaître chaque exploitant, chaque propriété et chaque contrée pour assurer une surveillance efficace. Les recherches en cours montrent que les gardes champêtres appartiennent souvent aux mêmes groupes familiaux. En Côte-d'Or, les généalogies mettent en évidence les liens de parenté qui existent entre les différents titulaires à l'intérieur d'une même commune. De plus, ils gravitent dans l'entourage des membres du conseil municipal ${ }^{42}$. Les lignages cherchent à maîtriser les fonctions qui donnent un pouvoir sur le reste des habitants pour maintenir leur position sociale ou pour l'accroître. Il semble également que les gardes aient d'abord été recrutés dans des familles qui ont exercé des fonctions de police ou de justice sous l'Ancien Régime, comme le suggèrent de nombreux exemples en Côte-d'Or. Quand différents réseaux s'affrontent pour le contrôle d'une municipalité, l'installation d'un conseil opposé au précédent se traduit fréquemment par un conflit avec les gardes champêtres en poste car ils sont jugés dévoués à l'ancien maire. En fait, ces crises mettent en jeu l'image que les ruraux se font de ceux qui sont chargés de les protéger.

En 1789, les gardes sont au service de la communauté d'habitants qui les nomme et à qui ils doivent rendre des comptes quand les auteurs de dégâts ne sont pas identifiés. Dès le Directoire, les nominations résultant d'un choix de l'assemblée générale des habitants sont considérées comme illégales et systématiquement annulées. Les villageois perdent prise sur le recrutement et le contrôle des employés qui les servent. La réforme de 1820 constitue une nouvelle étape dans le recul de leur influence, puisque le conseil municipal, qui les représente, est relégué à un rôle consultatif. La loi de 1837 accentue cette évolution. En parallèle se dessine la perte d'autonomie des communautés villageoises et leur dissolution car la direction de

\footnotetext{
40 A.N., F/2/136/1, lettre adressée au ministre de l'Intérieur.

41 A.N., F/2(I)/1210, Nord, lettre du préfet au ministre de l'Intérieur du 16 novembre 1821.

42 Gaveau (1997).
} 
l'espace commun, qui rapprochait tous leurs membres, leur échappe de plus en plus. Jusque vers 1789 , chaque chef de foyer y participait par sa présence aux assemblées des villageois. Si l'influence de chacun variait selon sa position sociale, le sentiment de peser sur les règles de vie collective existait. Après la Révolution, une minorité de représentants, les conseillers municipaux, héritent de cette attribution. Dans ce contexte, le garde champêtre devient de plus en plus clairement l'homme du maire. Il doit faire respecter des arrêtés et des lois que les habitants n'ont pas tous discutés, comme les règlements visant à limiter la vaine pâture, le glanage ou le grappillage. Il devient la figure d'un ordre dont la définition échappe à la majorité des villageois au profit de l'Etat et du maire dans son conseil.

Théoriquement, la loi organise la surveillance des gardes champêtres afin que des pratiques prohibées ne soient pas tolérées par les maires. Cependant, appliquer le droit dans toute sa force est un exercice délicat pour un préfet, a fortiori pour un sous-préfet, qui doit, autant que possible, éviter de heurter les notables de son ressort, fondement du régime censitaire. La recherche d'une majorité ministérielle oblige l'administration à beaucoup de doigtét $e^{43}$. Par ailleurs, s'attaquer au pouvoir des maires peut sembler une dérive autoritaire dont les gouvernements ne veulent pas donner le sentiment. Ainsi, la loi municipale de 1837 ne remet pas en cause la subordination des gardes aux maires. Malgré les aménagements introduits en faveur d'un renforcement du pouvoir administratif, l'insatisfaction à l'égard de la police rurale se maintient.

\section{RÉFORMER LA POLICE RURALE: L'ÉCHEC DE L'EMBRIGADEMENT}

\section{La formulation des plaintes}

Les conseils généraux et d'arrondissement se plaignent de la police rurale avec insistance, sans qu'il s'agisse toujours d'une initiative propre. En effet, ces assemblées sont liées aux préfets et aux sous-préfets qui fixent le cadre des discussions à l'ouverture de chaque session. Si le ministère de l'Intérieur souhaite que des mesures soient prises, il consulte par ce biais les notables du pays. Cependant, les conseils sont libres de formuler des vœux, surtout après les lois de 1833 et de $1838^{44}$. Ils discutent parfois de plaintes qui émanent de notables locaux. Les demandes des conseils d'arrondissement sont examinées par le conseil général dont les vœux sont étudiés par les bureaux des ministères compétents. Si, par son rapport, un préfet habile peut susciter un vœu ou en empêcher l'expression, la docilité des conseils n'est pas acquise pour autant. Deux exemples éclairent ce fonctionnement.

En Côte-d'Or, les membres des comités d'agriculture, férus d'agronomie, protestent contre les atteintes subies par leurs propriétés et qui entravent leur action en faveur du progrès. Le Joumal d'agriculture et d'horticulture de la Côte-d'Or, émanation du Comité central d'agriculture du département, s'en fait l'écho. En 1840, deux membres publient une lettre au préfet sous la rubrique «demandes - vœux état de l'agriculture » de leur périodique. Ils y dénoncent «l'accroissement scandaleux pour le présent, et véritablement inquiétant pour l'avenir, du nombre de délits

\footnotetext{
43 Tudesq (1982).

44 Tudesq (1967, pp. 185-186). Jusqu'en 1833, les conseils peuvent émettre des vœux mais touchant uniquement à l'intérêt général.
} 
ruraux, qui bientôt, grâce à l'incurie des gardes champêtres, aura pour conséquence inévitable le partage par moitié de la récolte entre les délinquans et les propriétaires ${ }^{45}$. Les vols dont il s'agit sont essentiellement liés aux pratiques communautaires qui procurent aux ruraux sans terre un complément de ressources. La tolérance de ces pratiques par les gardes soulève la colère de nombreux exploitants, ce qui témoigne de la décomposition des solidarités locales. Le conseil d'arrondissement de Dijon reprend les plaintes et demande l'embrigadement des gardes champêtres. Les conseils d'arrondissement de Châtillon-sur-Seine et de Semur-en-Auxois émettent le même souhait depuis les années 1820 , celui de Beaune depuis 1811 . Cependant, le conseil général refuse jusqu'en 1843 de prendre en compte cette question ${ }^{46}$. Dans un premier temps, les préfets n'ont pas jugé utile de considérer les demandes à ce sujet. Enfin, avec l'élection des conseillers, l'opposition à la monarchie de Juillet entre au conseil général et parvient à s'y faire entendre. Elle refuse de renforcer le pouvoir de répression de l'État.

Le Lot offre une configuration opposée. Le conseil d'arrondissement de Cahors demande à partir des années 1830 à rendre effective la présence des gardes champêtres dans chaque commune ou, à défaut, désire que plusieurs puissent s'associer pour partager les frais de l'emploi. Le conseil général et le préfet accueillent très favorablement la demande car il existe une convergence d'intérêts entre les notables et l'administration ${ }^{47}$. Certains veulent que les dégâts dans les bois cessent. D'autres considèrent la propriété en danger par l'expression plus forte des républicains. Godefroy Cavaignac, qui a des attaches à Gourdon, participe activement à leur organisation nationale dans les années $1830^{48}$. Par ailleurs, la force des démocratessocialistes en 1849 montre qu'ils se sont structurés sous la monarchie de Juillet, en relation avec les départements voisins. Ils sont surtout implantés dans le nord des arrondissements de Figeac et de Gourdon mais tiennent quelques solides positions à Catus et Cahors. Les sociétés secrètes y ont développé des ramifications. Dans les cantons de Saint-Céré et de Bretenoux, les républicains forment parfois la majorité des conseils municipaux ${ }^{49}$. Leur activité inquiète des notables encore marqués par le souvenir des révoltes paysannes qui ont bouleversé la région de 1791 à $1793^{50}$. Enfin, le modèle d'organisation militaire séduit les bonapartistes du département parmi lesquels apparaissent Murat et Ambert. La demande d'ordre est telle que les aspects financiers ou politiques liés à l'embrigadement des gardes ne sont pas perçus comme des obstacles.

Face aux insatisfactions, les ministères successifs paraissent hésitants. Depuis la Révolution, ils opposent généralement un calendrier de discussions incertain aux demandes de réorganisation de la police locale.

Le préfet de l'Oise fait remarquer en l'an IX qu'il faut régler la question du salaire des gardes pour développer leur zèle. Le ministère souligne avec contentement que

45. Barras et Bonnet (1840, p. 2).

46 A.D.C.O., 1/N/c/1 à 6, sessions du conseil général, 1811-1843.

47 A.D.L., 1/N/27, 1/N/28 et 1/N/29, sessions du conseil général, 1840-1854.

48 Gilmore (1997).

49 A.D.L., notamment 1/M/205, rapport des sous-préfets et des juges de paix sur l'opinion des conseils municipaux en 1850 et $1 / \mathrm{Per} / 8 / 1, L^{\prime}$ Écho du Lot, $1849, \mathrm{n}^{\circ} 95$ du 7 mars 1849.

50 Ado (1996). 
ces observations seront utiles au moment d'établir un code rural mais déclare qu'il faut pour l'heure se contenter de la législation existante ${ }^{51}$. Dès l'an V, il avait averti les représentants de la Moselle qu'un comité travaillait à résoudre ce problème ${ }^{52}$. En l'an X, le préfet de Moselle adresse deux rapports au ministère de l'Intérieur pour souligner les défaillances de la police rurale. Une réponse lui annonce qu'ils ont été communiqués aux conseillers «chargés d'un travail sur le code rural, et ils ont dû y puiser des renseignements dont ils feront usage ${ }^{53}$. La rédaction de cet improbable code permet aux autorités d'ajourner les décisions. En août 1812, à la suite de nouvelles plaintes, une circulaire demande aux préfets de réfléchir à des solutions. Elle soumet notamment 1'idée d'embrigader les gardes champêtres à la façon des gendarmes. Les conseils généraux et d'arrondissement sont consultés. Les difficultés militaires de la France enterrent cependant l'initiative ${ }^{54}$. En 1816 , le ministère ploie sous les mêmes plaintes. À la suite d'une demande du conseil général d'Indre-etLoire, une note du bureau de l'Agriculture fait savoir que «beaucoup d'autres conseils généraux ont exprimé leur vœu sur l'organisation (des gardes champêtres). Ce ne sera qu'après que toutes leurs délibérations sur cet objet auront été examinées que le gouvernement pourra prendre une détermination ${ }^{55}$. En somme le ministère cherche à ménager les notables et attend le moment opportun pour proposer une réforme d'envergure. En novembre 1815 , le préfet de l'Allier, qui avait institué dans son département l'embrigadement, est vertement rappelé à l'ordre. Sur le fond, le ministère apprécie l'intérêt de son subordonné pour la défense des propriétés. Cependant, sur la forme, il précise que «toute innovation aurait une apparence d'arbitraire et pourrait exciter de la part des communes une résistance d'autant plus embarrassante que les actes du préfet ne seraient pas appuyés sur les lois ${ }^{56}$.

Le retour des Bourbons au pouvoir, le climat de vengeance dont témoigne la seconde terreur blanche, l'occupation, et la crise liée à la liquidation de l'Empire constituent un bien mauvais contexte pour prendre des mesures autoritaires dans le domaine de la police locale. Les finances publiques manquent d'ailleurs pour assurer une telle réorganisation. Sous la monarchie de Juillet, dans un autre contexte, le ministère de l'Intérieur maintient la même attitude. Dès mars 1831, il répond à une demande d'embrigadement émise par le maire d'Ebblinghen dans le Nord en soulignant «que déjà à plusieurs époques ce projet a donné lieu à un examen approfondi de la part du gouvernement et que cet examen a fait reconnaître qu'il n'était pas possible de l'adopter ${ }^{57}$. L'État ne souhaite pas mettre en place une seconde gendarmerie rurale.

\section{L'action de la Chambre: I'exemple du député Félix de Saint-Priest}

L'inertie ministérielle conduit des députés à saisir la Chambre pour répondre aux doléances restées sans réponse. En 1843, une proposition de loi visant l'embrigadement est déposée par un député du Lot, Félix de Saint-Priest.

\footnotetext{
5! A.N., F/2(I)/1210, Oise, lettre du ministère au préfet du 7 frimaire an IX.

52 A.N., F/2(I)/1210, Moselle, lettre aux représentants de la Moselle à la Chambre du 6 thermidor an V.

53 A.N., F/2(I)/1210, Moselle, lettre du bureau de l'Agriculture au préfet du 23 nivôse an X.

54 A.N., F/2(I)/1205, Allier, circulaire du 17 août 1812.

55 A.N., F/2(I)/1208, Indre-et-Loire, brouillon d'une note du 27 juillet 1816, pour répondre au préfet.

s6 A.N., F/2(I)/1205, Allier, brouillon d'une lettre adressée au préfet le 25 novembre 1815.

57 A.N., F/2(I)/1210, Nord, lettre du ministère du 29 mars 1831.
} 
L'homme, raillé par Victor Hugo pour sa laideur ${ }^{58}$, est une figure marquante du Quercy. Sa famille, originaire de Tulle, a exercé d'importantes charges policières et judiciaires sous l'Ancien Régime. Son père, dont les biens ont été menacés par les révoltes paysannes sous la Révolution, est présenté en août 1815 par le préfet provisoire du Lot comme l'un des principaux organisateurs de la résistance à Napoléon dans le nord du département, où son mariage l'a conduit ${ }^{59}$. Après des études en droit à Toulouse, Félix de Saint-Priest est devenu avocat. Il vit surtout du revenu de ses propriétés qui s'étendent autour de Saint-Céré, où il réside et dont la municipalité est réputée ultra-conservatrice sous le règne de Charles $X^{60}$. En 1839 , il est élu conseiller général du canton de Bretenoux dont le chef-lieu a longtemps été administré par son père. Il demeure membre de l'assemblée départementale jusqu'à son décès en juin 1851. Il ajoute à cette charge celle de député à partir du 9 juillet 1842 . Il est élu par le collège de Martel avec 132 voix contre 89 au député sortant, un maître de forges. Il bénéficie alors dans le Lot d'une image favorable, notamment grâce à un discours teinté de libéralisme. Cependant, c'est un libéralisme à la façon de Berryer dont il partage la pensée politique. En effet, Saint-Priest est avant tout attaché à une vision chrétienne et paternaliste de la société. L'idée qu'il a de sa noblesse le conduit à se proclamer le défenseur des pauvres, comme le prouve son testament ${ }^{61}$. Ses adversaires le qualifient de jésuite tant ses convictions religieuses sont fortes et publiques ${ }^{62}$. Si son activité parlementaire se manifeste dans de nombreux domaines comme les rentes, la poste, les voies navigables, il agit tout particulièrement pour améliorer le maintien de l'ordre dans les campagnes en s'intéressant aux gardes champêtres et aux gendarmes. Ses origines, son histoire familiale et sa profonde crainte des «partageux » expliquent en partie ses efforts.

Déposée le 13 mai 1843 , sa proposition d'embrigadement est sa première grande intervention à la Chambre. Le texte en est bref et propose de placer les gardes «sous la direction d'un chef, au chef-lieu de canton. Ils n'en resteront pas moins soumis, pour le service communal, à la surveillance de l'autorité municipale, conformément à la loi du 10 octobre $1791 »^{63}$.

Pour en justifier le dépôt, il rappelle que les conseils généraux protestent «depuis plus de vingt ans» d'un bout à l'autre du territoire, du Var au Nord, de la Vendée au Doubs contre les faiblesses de la police rurale ${ }^{64}$. "Quand un mal se produit avec cet ensemble, avec cette généralité, il y a nécessité pour la législature d'y porter remède». De son point de vue, le fonctionnement du pouvoir municipal est en cause. Si les gardes champêtres remplissent mal leur rôle, c'est moins par incapacité ou par incompétence que par soumission à une autorité qui se moque des lois ou les ignore. À l'appui, Saint-Priest mène une comparaison avec la situation issue du code forestier de 1827 et de la loi sur la pêche fluviale de 1829. «Tandis que

58 Hugo $(1972$, p. 367).

59 A.D.L., J/183, lettres concernant François de Saint-Priest de 1814 à 1816 , certificat du 26 août 1815 .

60 Bertier de Sauvigny (1974, p. 202).

61 A.D.L., 1/Per/10/1, Le Courrier du Lot, ${ }^{\circ} 192$, samedi 17 mai 1851.

62 A.D.L., 1/Per/8, L'Écho du Lot, $n^{\circ} 113$, jeudi 26 avril 1849 . Le journal, fidèle à Saint-Priest, dénonce les attaques dont il est l'objet.

63 Le Moniteur Universel (1843, p. 1106). Il évoque là le décret sur les biens et usages ruraux des 28 septembre-6 octobre 1791 .

${ }^{64}$ Ibidem, Félix de Saint-Priest défend sa proposition, p. 1239. Toutes les citations qui suivent en proviennent. 
les contraventions rurales ne sont pas réprimées, il y a un autre genre de méfaits qui reçoit une répression sévère. Je veux parler des délits forestiers ». D'après lui, si les gardes forestiers semblent efficaces cela tient à une organisation de type militaire. Il ne note pas en revanche que les forêts sont soigneusement surveillées car elles procurent des revenus importants aux communes, à l'État et car les maîtres de forges en retirent du charbon et du combustible. Saint-Priest ajoute que la gendarmerie doit à sa solide structure militaire son exemplarité. Pourquoi, alors, refuser d'étendre aux gardes champêtres le même modèle?

La nouvelle hiérarchie qu'il envisage s'arrête au canton. Rien n'est prévu quant à l'éventuelle coordination des brigadiers qui dirigeraient tous les gardes. Dépendraient-ils du sous-préfet de l'arrondissement, qui conserve son droit de nomination? De la gendarmerie, par application de l'ordonnance royale d'octobre 1820 ? Saint-Priest rétorque par avance à ceux qui lui reprocheront d'attenter au pouvoir municipal, qu'il en respecte les droits. Toutefois, il pense utile de diminuer "ce droit d'administrer que les maires se sont arrogés». En effet, le maire est à la fois le défenseur des intérêts de la commune, le représentant des habitants et un fonctionnaire au service de l'État. Or, pour Saint-Priest, les gouvernements successifs lui ont abandonné des compétences étendues sans prendre de précautions suffisantes quant à leur exercice. Un maire peut entraver l'action de la police car il en est le responsable dans sa commune. Saint-Priest souhaite que l'État reprenne en main les pouvoirs régaliens qu'il a, à tort, éparpillés. La police en fait partie. Il précise que le garde champêtre «n'est pas seulement l'homme de la commune, il est aussi l'homme de la sûreté publique ». Son action contribue à la défense de la société dans son ensemble. Elle touche à l'intérêt de la France par-delà les intérêts particuliers. D'après son projet, les gardes résideraient dans les communes et assureraient ainsi une police de proximité. Toutefois, l'embrigadement permettrait de les faire patrouiller dans tout le canton. Leur autorité s'exercerait sur plusieurs communes indépendamment des influences municipales. Par ce système, les gardes s'épauleraient et ne craindraient plus de sévir contre les délinquants. Une telle réforme suppose une révision du mode de traitement de ces employés dont le service dépasserait les limites d'un finage.

Saint-Priest estime qu'en l'état, «les 6 ou 7 millions que reçoivent les gardes champêtres ne sont pas motivés par les services qu'ils rendent, ou, en d'autres termes, leurs services actuels ne valent pas les sacrifices qu'on fait pour eux $\gg^{65}$. Il déclare être décidé à faire voter la suppression de leur traitement des dépenses communales si la situation n'évolue pas, afin d'abréger un tel gaspillage. Il souhaite revenir à un mode antérieur à la loi de 1832. Les gardes seraient payés sur le produit des amendes, qu'une amélioration de la police rurale ne doit pas manquer d'accroître considérablement. Sa pensée trouve là une faille. Le maintien d'un nombre élevé de délits permet le fonctionnement de la réforme proposée. Si, en revanche, l'amélioration se traduit par le recul de la délinquance, les communes auront à supporter la charge financière de la nouvelle organisation. Il pense que l'augmentation des effectifs de police se traduira par l'accroissement du nombre de délits constatés, pour le plus grand bien des campagnes, dont il rappelle qu'elles « apportent en tribut aux villes le produit de leurs sueurs; qu'elles apportent au budget bien des millions,

65. Le Moniteur Universel (1843, p. 1239). Les citations suivantes en sont issues. 
et peut-être supportent les trois quarts de l'impôt foncier». Il prouve ainsi que le sacrifice financier éventuellement demandé à l'État et aux communes pour rétribuer les gardes sera largement compensé par l'amélioration du rapport des terres, dont tous les propriétaires profiteront.

Par la réforme de la police, qui lui paraît singulièrement en crise, Saint-Priest souligne qu'il cherche à défendre l'ordre social. Il livre à la Chambre «la pensée fondamentale de (sa) proposition: je crois qu'il n'y aura jamais de bons services pour la société où il n'y aura pas hiérarchie, discipline et subordination ». Il défend une vision aristocratique des structures sociales et politiques, ce qui caractérise la pensée légitimiste ${ }^{66}$. L'organisation de la police induit un discours sur l'État et, à travers lui, sur la société car elle garantit l'un et l'autre. Par l'embrigadement, SaintPriest souhaite appliquer aux gardes champêtres une organisation de type militaire. Elle suppose la définition d'une hiérarchie en fonction de grades qui correspondent à des tâches et à des responsabilités diverses. Les échelons de l'édifice trouvent un ancrage dans les circonscriptions territoriales et encadrent tous les habitants. Enfin, les gardes sont soumis à l'unité d'un commandement dont la source est un État centralisé, fort, qui procure sécurité et pérennité à la société. Saint-Priest distingue ainsi l'État, qui sert la société, et la société, dont le corps politique, dépositaire de la souveraineté nationale, produit l'État. Pour agir, il est doté de structures - les institutions - définies par les représentants de la nation. Son efficacité est liée à sa capacité à s'affranchir des intérêts particuliers et à briser les volontés contraires au projet dont il assure la réalisation. Il est donc à la fois une force d'exécution de la volonté générale et une force de coercition qui naît de la nation et lui est supérieure tout en la servant.

Cette figure de l'État fait pendant à la perception que Saint-Priest a de la société. Pour lui, l'affirmation de l'égalité civile a retiré à la noblesse et aux corps intermédiaires, qui forment des structures d'encadrement social, tout contrôle et toute action sur la société au profit du corps politique des citoyens actifs. Ce phénomène résulte du développement de la pensée libérale qui recherche l'épanouissement de chaque individu en lui garantissant la liberté et des droits politiques. Ces droits permettent aux citoyens de prendre en main leur destin et d'exercer l'autorité publique dans le cadre d'un gouvernement représentatif. Saint-Priest estime que l'État doit suppléer la destruction des hiérarchies sociales car un esprit individualiste se répand, qui sape les liens de solidarité et laisse les plus faibles démunis face à ceux qui exercent, par délégation, des pouvoirs régaliens. La pensée libérale cherche au contraire à limiter la puissance de l'État pour garantir l'exercice des droits individuels. Ainsi les libéraux mettent en avant l'esprit de municipalité contre la centralisation de l'administration qui entrave la liberté des citoyens. Ceux-ci ne doivent pas dépendre d'un État omnipotent mais doivent être associés à l'exercice du pouvoir dans les communes et dans les départements, ce qui permet aussi la prise en compte d'habitudes de vie propres à chaque région. La monarchie de Juillet répond d'ailleurs en partie à cette attente par les lois municipales de 1831 et 1837 et par les lois sur les conseils généraux de 1833 et 1838 .

En définitive, en déclarant la police rurale en crise, Saint-Priest attire l'attention de ces collègues sur les menaces d'affaiblissement de l'État du fait d'un libéralisme 
destructeur. Il redoute l'atomisation de la société et la soumission des individus à des pouvoirs locaux, qui détournent l'autorité publique dont ils sont les dépositaires et les représentants, au service d'intérêts particuliers. En proposant de réorganiser la police rurale il souhaite contribuer à la restructuration d'un État fort incarnant la Nation et défendant la propriété et la religion, socles de l'ordre social.

\section{Le refus du modèle militaire}

La Chambre approuve dans un premier temps l'exposé de Saint-Priest et reconnaît que la police rurale ne donne pas satisfaction. Les députés sont favorables à une réforme. Cependant, la proposition est ajournée. D'un point de vue financier, la difficulté est de déterminer qui devrait rétribuer les gardes embrigadés et sur quels fonds. Les députés ne sont pas favorables à l'augmentation des charges de l'État et ils estiment que les moyens dont les communes disposent sont trop limités.

En écho aux préoccupations du corps législatif, le gouvernement décide cependant de profiter d'une enquête à propos de la gestion des biens communaux pour consulter les conseils généraux sur la police rurale. Ces deux domaines cachent un même enjeu, celui du pouvoir accordé aux municipalités. Comme le rappelle $\mathrm{N}$. Vivier, «l'administration des communaux constitue le principal domaine de liberté de décision accordé aux conseils municipaux par la loi de 1837. C'est pourquoi toute loi qui y porterait atteinte serait très mal perçue $"{ }^{67}$. De la même façon, priver les maires d'une partie de leur pouvoir de police risque de soulever de vives oppositions. Or le régime de Juillet tient à ménager ses assises notabiliaires et libérales. L'organisation d'une consultation permet au gouvernement de mesurer la marge dont il dispose pour entreprendre ou non des réformes. Il souligne aussi que s'il respecte les avis de la Chambre, il tient à ceux des notables sur lesquels la vie politique repose.

Les réponses des conseils généraux révèlent les lignes de partage que SaintPriest faisait observer mais qu'il avait sous-estimées. Dans son département, le Lot, le conseil d'arrondissement de Cahors émet le vœu que son projet puisse être réexaminé «dégagé des difficultés financières qui l'ont fait ajourner ${ }^{68}$. Le conseil général, dont il est membre, appuie en ce sens et réfléchit à la mise en œuvre d'une telle réforme en affinant l'organisation de l'embrigadement ${ }^{69}$. D'autres départements sont plus nuancés. Dans la Creuse, le conseil d'arrondissement de Guéret est très favorable à l'embrigadement. Il permettrait de nommer des gardes champêtres, cruellement absents dans sa circonscription. Les trois autres conseils du département ne se prononcent pas. Les salaires devraient être répartis entre les communes, le département et l'État ${ }^{70}$. Cependant, la crainte d'augmenter les charges fiscales conduit le conseil général à exclure cette possibilité. D'autres départements expriment un refus plus argumenté. En Côte-d'Or, le conseil général reconnaît les carences du service champêtre mais déclare qu'il y aurait plus de désagréments encore à vouloir embrigader ces agents. Il en ressortirait «l'affaiblissement de l'autorité municipale et l'augmentation de dépenses ${ }^{71}$. Il repousse aussi l'idée de

\footnotetext{
67 Vivier (1998, p. 251).

68 A.D.L., 1/N/28, session de 1843 reprise par le conseil général du Lot.

69 Ibidem.

70 A.D.C., 2/N/38/1, session de 1843, rapport du sous-préfet.

71 A.D.C.O., $1 / \mathrm{N} / \mathrm{c} / 6$, session de 1843 , réponse du conseil général au rapport du préfet.
} 
«brigades de gendarmes ruraux» car il estime qu'elles «constateraient souvent des contraventions inoffensives que les cultivateurs tolèrent mutuellement $»^{72}$. À l'activité agricole sont immanquablement liés des risques de dégâts du fait du pâturage ou des passages nécessaires dans les finages. Les exploitants savent qu'ils y sont exposés. Un arrangement à l' amiable permet une réparation des dommages sans que les parties en présence n'éprouvent le besoin de faire intervenir la justice. Le conseil général de Côte-d'Or exprime surtout sa crainte à l'égard du renforcement de la police des campagnes qui pourrait être le prélude à l'appesantissement d'un pouvoir autoritaire. La majorité des conseils généraux exprime les mêmes réserves à l'idée d'embrigader les gardes.

Ainsi, aucun texte n'est soumis à la Chambre pour légiférer à ce sujet. Tous les projets d'embrigadement qui ont germé dans le pays depuis l'Empire ont été systématiquement repoussés. Le refus de la militarisation repose sur deux arguments majeurs : la peur d'accroître les dépenses publiques et la peur de diminuer le pouvoir local au profit de l'État central, ce qui heurte les notables imprégnés de libéralisme. Il s'explique aussi par le recul du prestige de tout ce qui a trait au modèle militaire sous la Monarchie censitaire, comme l'a montré R. Girardet ${ }^{73}$.

L'échec de 1843 ne fait pas taire ceux qui dénoncent les déficiences de la police des campagnes. En 1845, Félix de Saint-Priest dépose une proposition de loi visant à augmenter les effectifs de la gendarmerie ${ }^{74}$. Comme en 1843, sa proposition est refusée. En 1846, ce député est écarté de la Chambre grâce à l'action de l'administration qui soutient contre lui la candidature de Calmon fils, conseiller d'État et président du conseil général du Lot. Il retrouve sa fonction sous la Seconde République, en 1848. Proche du Comité de la rue de Poitiers, où s'organise le parti de l'ordre, il est alors présenté par son journal, L'Écho du Lot, comme rallié à « une République de calme et de liberté $»^{75}$. Ses partisans préviennent les démocrates-socialistes que c'est à lui «qu'on devra plus tard [...] l'extension de la gendarmerie, ce qui (les) gênerait ${ }^{76}$. Les rouges sont clairement considérés comme des fauteurs de troubles d'où les revendications exacerbées en faveur d'une amélioration du dispositif policier dans les campagnes; où leur influence s'étend. Saint-Priest est d'ailleurs désigné pour participer à une commission d'initiative parlementaire chargée d'examiner une proposition de loi présentée par un député légitimiste de l'Hérault, Girard, concernant l'embrigadement des gardes champêtres. Lui aussi est confronté à la montée des rouges et demande plus d'ordre dans les campagnes. Ainsi, en mai 1848, à La Salvétat-sur-Agout, les habitants s'emparent des communaux qui avaient été aliénés et des troubles éclatent dans tout le département ${ }^{77}$. Malgré le ralliement de nombreux conseils généraux - comme celui de Côte-d'Or - la Chambre repousse l'idée d'embrigader les gardes champêtres en 1851 en avançant des motifs en partie comparables à ceux présentés en 1843. À la crainte de dépenser plus que le service ne le mérite, s'ajoute l'idée que la police rurale doit être réorganisée dans le cadre de la réforme des municipalités et des cantons que la Seconde République

\footnotetext{
72 Ibidem.

73 Girardet (1998).

74 Le Moniteur Universel (1845, p. 1452). Intervention de Félix de Saint-Priest.

75 A.D.L., 1/Per/8, $\mathbf{n}^{\circ} 91$ du mercredi 21 février 1849.

76 Ibidem, $\mathrm{n}^{\circ} 113$ du jeudi 26 avril 1849 .
}

77 Archives départementales de l'Hérault, rapport imprimé du préfet au conseil général, 1849. 
annonce. Par ailleurs, Saint-Priest n'a pas pu faire entendre sa voix car la maladie, qui l'emporte le 12 juin 1851, l'a tenu à l'écart de la Chambre à partir de 1850.

\section{CONCLUSION}

Après le coup d'État de décembre 1851, la police rurale est réorganisée autour de quelques axes, qui satisfont une majorité de notables ralliés au parti de l'ordre. Le décret du 25 mars 1852 redéfinit les pouvoirs des préfets en matière de nomination aux emplois publics. Ils héritent du soin de nommer sans en référer au gouvernement divers fonctionnaires, parmi lesquels se trouvent les gardes champêtres. Les maires présentent les candidats mais n'ont plus l'assurance d'installer les personnes qu'ils désignent et qui font l'objet d'une enquête de capacités et de moralité. Le passé militaire des postulants devient un élément déterminant dans leur nomination. Le 31 décembre 1852, des commissaires de police cantonaux sont institués. Ils sont spécialement chargés de veiller au zèle des gardes champêtres et de tenir les autorités informées de l'état de l'opinion dans leur ressort. Chaque canton en abrite un. Toutes les communes se réunissent pour lui assurer son traitement. À partir de mars 1853, les commissaires dépendent d'un supérieur départemental, soumis au préfet. Enfin, des mesures sont prises pour accroître les effectifs de la gendarmerie, à qui profite la forte demande d'ordre. D'ailleurs, la grande loi de 1854 redéfinit son service. En conséquence, la police rurale offre l'exemple d'un domaine largement critiqué par les notables mais dont la réforme achoppe sur l'opposition des libéraux. Tous recherchent une solution idéale qui se traduirait par le développement d'une conscience professionnelle plus grande chez les gardes - ce que chacun appelle le zèle - sans mettre en cause leur soumission aux autorités municipales, sans renforcer le pouvoir de l'État central et sans augmenter leur rétribution, pour ne pas risquer d'accroître les dépenses des communes ou de l'État. La solution paraît difficile à élaborer. Cette situation explique la facilité avec laquelle les plaintes remontent jusqu'au gouvernement ou à la Chambre. En effet, la nécessité d'assurer la protection des propriétés rassemblent tous les notables. Pourtant, les enjeux d'une telle réforme paralysent l'action des autorités. Le compromis était d'autant plus introuvable que l'embrigadement proposé aboutissait à la création d'une force qui aurait pu être assimilée à un double de la gendarmerie au service du ministère de l'Intérieur. Le problème de l'articulation de cette force avec les gendarmes soumis au ministère de la Guerre se serait posé. Enfin, opter pour le renforcement de la surveillance des gardes offre, outre l'avantage financier, celui de ménager les maires en leur laissant une prise sur ces agents. La question témoigne enfin des difficultés qu'éprouvent les notables à penser la formation des agents de l'ordre et la coordination des diverses forces instituées à cet effet. Les mutations de la société dans la seconde moitié du $\mathrm{XIX}^{\mathrm{e}}$ siècle reporteront ces difficultés sur la police des villes et des voies de communications, posant avec une nouvelle acuité la question de l'efficacité des forces de l'ordre.

Fabien Gaveau

Chemin de Valoup

F-21500 Quincy-le-Vicomte 


\section{RÉFÉRENCES}

Ado, A., Paysans en révolution. Terre, pouvoir et jacquerie 1789-1794, Paris, Sociétés des Études Robespierristes, 1996 (traduction revue et complétée d'après la seconde édition russe de Les paysans et la Révolution française. Le mouvement paysan en 1789-1794, Moscou, Éditions de l'Université de Moscou, 1987).

Aubusson de Cavarlay, B., Huré, M.-S. et Pottier M.-L., Les statistiques criminelles de 1831 à 1981. La base Davido, séries générales, Paris, C.E.S.D.I.P., 1989, 51.

Balzac, H. de, Les paysans, Paris, Folio, 1993.

Barras et Bonnet, Lettre au préfet du 6 décembre 1840, Joumal d'agriculture et d'horticulture de la Côte-d'Or, Dijon, 1840, p. 2.

Berlière, J.-M., Le monde des polices en France (XIX ${ }^{e}-X X^{e}$ siècles), Bruxelles, Complexe, 1996.

Bertier de Sauvigny, G. (de), La Restauration, Paris, Flammarion, 1974.

Brissot de Warville, E., Traité de police municipale et rurale, Paris, $2^{\mathrm{C}}$ édition, 1846.

Carrot, G., Histoire de la police française, Paris, Tallandier, 1992.

Cere, P., Manuel du fonctionnaire chargé de la police judiciaire, administrative et municipale, Paris, Cotillon, 1854.

Crebouw, Y., Salaires et salariés agricoles en France des débuts de la Révolution aux approches du XX $X^{e}$ siècle, Paris, Thèse Lettres, 1984, 4 volumes.

Dupâquier, J. (Dir), Histoire de la population française. 3, de 1789 à 1914, Paris, P.U.F., 1988, réédition «Quadrige», 1995.

Duquesnel, M., Lois municipales, rurales, administratives et de police, Paris, 2 volumes, 1830-1831.

Festy, O., Les délits ruraux et leur répression sous la Révolution et le Consulat. Étude d'histoire économique, Paris, M. Rivière, 1956.

Forestier, H., Les salaires des cantonniers de 1789 à 1859 dans l'Yonne, Bulletin de la Société des Sciences Historiques et Naturelles de l'Yonne, 1953-1956, pp. 363-376.

Gaveau, F., L'ordre aux champs. Pour une histoire des gardes champêtres (1789 - années 1880), Dijon, mémoire pour l'obtention du D.E.A. d'histoire, 1997, 2 volumes.

Gilmore, J., La République clandestine 1818-1848, Paris, Aubier, 1997.

Girardet, R., La société militaire de 1815 à nos jours, Paris, Perrin, 1998.

Herbert, J., Être garde champêtre au XIX ${ }^{\mathrm{e}}$ siècle (dans le Nord), Jadis en Cambrésis, 1994, 33, pp. 19-33.

Hugo, V., Choses vues. Souvenirs, journaux, cahiers, 1847-1848, Paris, Folio, édition établie par Hubert Juin, 1972.

Laurent, E., Gardes champêtres, in Bequet, L. (Dir.), Répertoire du droit administratif, Paris, Paul Dupont, 1900, Tome 17, pp. 385-392.

Le Moniteur Universel, 1843, séance du samedi 13 mai.

Le Moniteur Universel, 1845, séance du lundi 26 mai.

Miriel, E., Des rapports des municipalités et du pouvoir central en matière de police, Paris, Thèse de droit, 1897.

Cuvres judiciaires du président Henrion de Pansey, Paris, Librairie générale de jurisprudence de Cosse et N. Delamotte, 1844.

Rémond, R., La droite en France de 1815 à nos jours. Continuité et diversité d'une tradition politique, Paris, Aubier, 1954.

Rosanvallon, P., L'État en France de 1789 à nos jours, Paris, Le Seuil, 1990. 
Santucci, M.-R., Délinquance et répression au XIX siècle. L'exemple de l'Hérault, Paris, Economica, 1986.

Signorel, H., Le garde champêtre, officier de police judiciaire, Toulouse, 1931.

Tocqueville, H. (de), Instruction sur les obligations imposées aux gardes champêtres, Dijon, Frantin, 1816.

Tudesq, A.-J., Les conseillers généraux en France au temps de Guizot, Paris, A. Colin-FNSP, 1967.

Tudesq, A.-J., Parlement et administration sous la monarchie de Juillet, in Bonnefous, E., (Dir.), Administration et parlement depuis 1815, Genève-Paris, Droz - École Pratique des Hautes Études-Champion, 1982, pp. 13-37.

Vivier, N., Propriété collective et identité communale. Les biens communaux en France 1750-1914, Paris, Publications de la Sorbonne, 1998. 